\title{
"Lo ético es transversal y cotidiano": dimensiones éticas en la formación y práctica en psicología comunitaria
}

\author{
María Inés Winkler ${ }^{1}$, Katherine Alvear², Bárbara Olivares ${ }^{2}$, Diana Pasmanik ${ }^{3}$
}

Resumen: La psicología comunitaria ha vivido grandes transformaciones asociadas al devenir histórico y contextual en nuestro país, comportando una serie de cuestiones éticas que no han sido abordadas ni en la formación ni en la deontología disciplinar. Objetivo de esta investigación fue indagar la percepción de estudiantes y profesionales respecto de la ética en la práctica y la formación en psicología comunitaria. Nuestros participantes fueron expertos chilenos, estudiantes en práctica y estudiantes de dos programas de Magíster en psicología comunitaria con tres fuentes de datos: panel Delphi (8 expertos), entrevistas en profundidad ( 7 maestrandos) y grupos focales (20 estudiantes en práctica comunitaria). Aplicando los principios de la teoría fundamentada empíricamente, el análisis de datos decantó en la identificación de cuatro temas: noción de lo ético, tipos de situaciones éticas, formación ética y deontología. Entre los resultados destaca el carácter, simultáneamente, "transversal y cotidiano" así como "vago" de la dimensión ética en el discurso de nuestros participantes. Frente a situaciones concretas, éstos identificaron principios éticos generales, verbalizados como Respeto por el Otro y Autonomía.

Palabras clave: psicología comunitaria, ética profesional, formación, deontología

\section{"Ethical issues are transversal and habitual": ethical dimensions in training and practice for community psychology}

\begin{abstract}
Community psychology has suffered huge transformations associated to a historical and contextual process in our country, involving a series of ethical issues which have not been dealt with both in training and deontological discipline. The aim of this research was to inquire the perception of students and professionals with respect to ethics in practice and training in community psychology. Our participants were Chilean experts, students in practice and students of two Master programs in community psychology with three data sources: Delphi panel (8 experts), in-depth interviews (7 master students), and focal groups (20 students in community practice). By applying the principles of the theory empirically based, data analysis showed the identifications of four topics: ethical notion, types of ethical situations, ethical training and deontology. Among the results, the simultaneous character of ethical dimensions "transversal and habitual" as well as "vague" was highlighted in the discourse of our participants. Considering concrete situations, these identified general ethical principles, which was verbalized as Respect for the Other and Autonomy.
\end{abstract}

Key Words: community psychology, professional ethics, training, deontology

\section{“O ético é transversal e cotidiano": dimensóes éticas na formação e prática em psicologia comunitária}

Resumo: A psicologia comunitária tem vivido grandes transformaçóes associadas ao devenir histórico e contextual em nosso país, comportando uma série de questôes éticas que não foram abordadas nem na formação nem na deontologia disciplinar. Objetivo desta investigação foi indagar a percepção de estudantes e profissionais a respeito da ética na prática e na formação em psicologia comunitária. Nossos participantes foram especialistas chilenos, estudantes em prática e estudantes de dois programas de Mestrado em psicologia comunitária com três fontes de dados: painel Delphi (8 especialistas ), entrevistas em profundidade (7 mestrandos) e grupos focais (20 estudantes em prática comunitária). Aplicando os princípios da teoria fundamentada empiricamente, a análise de dados decantou na identificação de quatro temas: noção do ético, tipos de situaçôes éticas, formação ética e deontologia. Entre os resultados destaca o caráter, simultaneamente, "transversal e cotidiano" assim como "vago" da dimensão ética no discurso de nossos participantes. Frente a situaçôes concretas, estes identificaram princípios éticos gerais, verbalizados como Respeito pelo Outro e Autonomia.

Palavras-chave: psicologia comunitária, ética profissional, formação, deontologia

\footnotetext{
${ }^{1}$ Profesora Titular y Directora Magíster en Psicología Clínica, Universidad de Santiago, Chile

Correspondencia: maria.winkler@usach.cl

${ }^{2}$ Docente, Universidad Católica Cardenal Silva Henríquez, Chile

${ }^{3}$ Profesora Asociada y Directora Magíster en Psicología Educacional, Universidad de Santiago, Chile
} 


\section{Introducción}

En Chile, desde la década de los 60, se ha reconocido la relevancia de enfoques que consideran a la comunidad en temas de salud y el abordaje de problemáticas psicosociales, siendo pioneros los trabajos de Marconi y Weinstein(1), surgidos en el ámbito médico-académico.

El contexto histórico moldeó ulteriormente el desarrollo de estos trabajos, siendo la institucionalización de la psicología comunitaria el más evidente, sistemático y creciente $(1,2)$. Se han reportado los cambios que la han caracterizado en Chile los últimos 15 años(3-5), así como también se ha documentado la formación, a partir del análisis de mallas curriculares y programas de asignaturas(6). De dichos estudios se desprende la necesidad de contar con lineamientos éticos específicos a su quehacer, dada su complejidad y especificidad, así como la ausencia de acuerdos y consensos respecto de aspectos éticos relevantes en la formación en psicología comunitaria(6-8).

En consonancia, el objetivo de este trabajo fue indagar la percepción de estudiantes de pre y posgrado y de académicos, respecto de la dimensión ética en la formación y en la práctica en psicología comunitaria, incluyendo tipos de problemas más frecuentes en el quehacer profesional y temas específicos que surgen en las prácticas comunitarias.

\section{Ética, moral y deontología: distinciones bási- cas}

Profusas superposiciones han surgido en el uso del lenguaje para las palabras "moral" y "ética"; por ejemplo, usamos "problema moral" en el mismo sentido que "problema ético". Si bien ambos vocablos provienen de palabras con significados similares -ética del griego ethos y moral del latín mos y ambos significan "costumbre", "uso", "hábito"-, es necesario asignarles un significado propio. Hartmann(9) propone dejar la expresión "ética" para designar a la disciplina filosófica que estudia la distinción entre el Bien y el Mal, abordando las diversas perspectivas en la naturaleza del compromiso moral. Así, la ética definirá el estudio de las creencias de las personas, instituciones $\mathrm{u}$ organizaciones que permiten distinguir entre lo correcto y lo incorrecto y hacer juicios morales, mientras que moral corresponderá al conjunto de los usos o prácticas que identifican a una forma de vida(10). Cortina(11) refuerza esta distinción concibiendo a la ética como filosofía moral y definiendo el quehacer ético como la tarea de "acoger el mundo moral en su especificidad y en dar reflexivamente razón de él"(11:43).

En psicología se ha estudiado los componentes del desarrollo moral, siendo pioneros los aportes de Kolhberg —en su relectura de Piaget-y de Gilligan, en su ética del cuidado. Pasmanik y Winkler(8) reseñan distintos modelos de transmisión de la ética en psicología, destacando que esta transmisión se ha centrado en el ámbito clínico: aprendizaje por osmosis o enseńanza de la ética, incidental, mediante la supervisión clínica; la combinación de psicología y filosofía en cursos de ética; los modelos de resolución de problemas y la formación en ética profesional como proceso de aculturación, que considera que los estudiantes desarrollan el sentido de sí mismos como profesionales éticos, adquiriendo progresivamente tradiciones, valores y métodos de la psicología, en tanto cultura.

En un ámbito en que confluyen práctica comunitaria y formación en ética, $\operatorname{Arratia}(12)$ plantea la relevancia de la acción docente al generar condiciones que promuevan la reflexión ética, la capacidad dialógica y la generación de conciencia crítica. En el modelo de Aprendizaje Servicio propone que los estudiantes deberían enfrentar necesidades comunitarias reales, identificando dilemas éticos y aplicando principios a situaciones concretas.

\section{Tensiones éticas en psicología comunitaria}

Diversos autores han manifestado la importancia de reconocer que la psicología comunitaria enfrenta temas y problemas éticos propios y característicos de sus desarrollos teóricos y prácticas profesionales. Tempranamente, Pope afirmaba: "Articular un conjunto de valores éticos aceptados en general y genuinamente aplicables, relevantes a las diversas metas y actividades de la psicología comunitaria es una tarea que debe ser abordada” (13).

Este llamado adquiere relevancia a la luz de los 
cambios que implica la llamada posmodernidad; en palabras de Sánchez Vidal(14): "uno de los planos que ha sufrido más dramáticamente los cambios y contradicciones es el ético".

Montero(15-17) reposiciona el tema ético elaborando la necesidad de añadir las dimensiones política y ética (a las dimensiones ontológica, epistemológica y metodológica, desarrolladas por Guba y Lincoln)(18) en el análisis de la construcción de conocimiento.

La necesidad de proponer una deontología específica es explicitada por Blanco(19), al especificar que la comunitaria tiene que ver, frecuentemente, con entidades supraindividuales, lo que debería ser considerado en la elaboración de un código deontológico para la profesión.

Paradojalmente, desde la empiria, la revisión de códigos de ética para psicólogos realizada por Winkler $(7,20)$ muestra la ausencia de referencias a situaciones de implicancia ética específicas de la psicología comunitaria.

Es así como, por una parte, la práctica profesional implica nuevos desafíos y dilemas, y, por otra, ello no es abordado en la formación ni por la comunidad profesional en la deontología. Ante esta falta de pautas, guías y normativas - lo que podríamos denominar "vacío ético"-, nos parece relevante conocer las percepciones y experiencias de estudiantes y profesionales - con distintos grados de experticia en el campo- respecto de las formas en que se manifiesta la dimensión ética en la práctica y la formación, los tipos de problemas éticos que enfrentan y sus representaciones de lo ético en el quehacer profesional.

\section{Métodos}

Esta investigación corresponde a un estudio exploratorio-descriptivo que, desde un punto de vista constructivo-interpretativo(21), supone que las diversas realidades se construyen dinámicamente en relación al contexto y a la interpretación de los propios actores sociales. Optamos por estrategias cualitativas, epistemológicamente consistentes con la psicología comunitaria, por su valoración de la diversidad, del contexto y de la acción y discursos de los sujetos sociales $(22,23)$.
Abordamos los objetivos propuestos a partir de 3 estrategias metodológicas:

Panel de expertos o método Delphi: proceso interactivo en que se envió cuestionarios a un grupo de expertos, cuyas respuestas fueron analizadas y devueltas en 3 ocasiones sucesivas, con el fin de aproximar consensos e identificar áreas de discrepancias(24). Seleccionados a partir de su experiencia en el área, como docentes y autores de publicaciones, para este artículo consideramos los aportes de los 8 psicólogos comunitarios chilenos.

- Cuatro grupos focales con 20 estudiantes de pregrado con práctica profesional en psicología comunitaria.

- Entrevistas en profundidad a 8 estudiantes de Magíster en psicología comunitaria.

Todos participaron de forma libre y voluntaria, proceso documentado a través de un consentimiento informado. Comprometimos la confidencialidad en el manejo de los datos, tanto en la identidad de los entrevistados como de sus filiaciones institucionales.

Para el análisis de los datos, seguimos criterios de la Teoría Fundada Empíricamente, específicamente la codificación abierta y selectiva(25), identificando y destacando las percepciones y experiencias comunes, independientemente del grado de formación y experticia de nuestros participantes.

\section{Resultados}

Los aspectos éticos asociados al quehacer y la formación en psicología comunitaria se organizan en cuatro categorías, que reflejan las representaciones y problemáticas que emergen desde la propia experiencia de los participantes.

1. Noción de lo ético en psicología comunitaria: contenidos asociados a la concepción de lo ético y referencias a lo que es considerado correcto o incorrecto en la formación y el ejercicio de la disciplina.

Aparecen significados que aluden a dimensiones globales, que expresan una cierta vaguedad de "lo ético", y que conciben "lo ético" como transversal 
y cotidiano. Las dimensiones aplicadas son referencias a cómo la ética se materializa en la práctica concreta, a través del respeto a la persona, el respeto por la autonomía y la importancia asignada a la "horizontalidad en la relación".

La adquisición de "lo ético" corresponde al reconocimiento de las instancias en que se generan las nociones de lo correcto e incorrecto, destacando la socialización primaria y secundaria (desde la familia, la escuela y la religión), la formación profesional y docentes o figuras marcadoras que muestran e inspiran el desarrollo de una sensibilidad ética, tal como se expone a continuación:

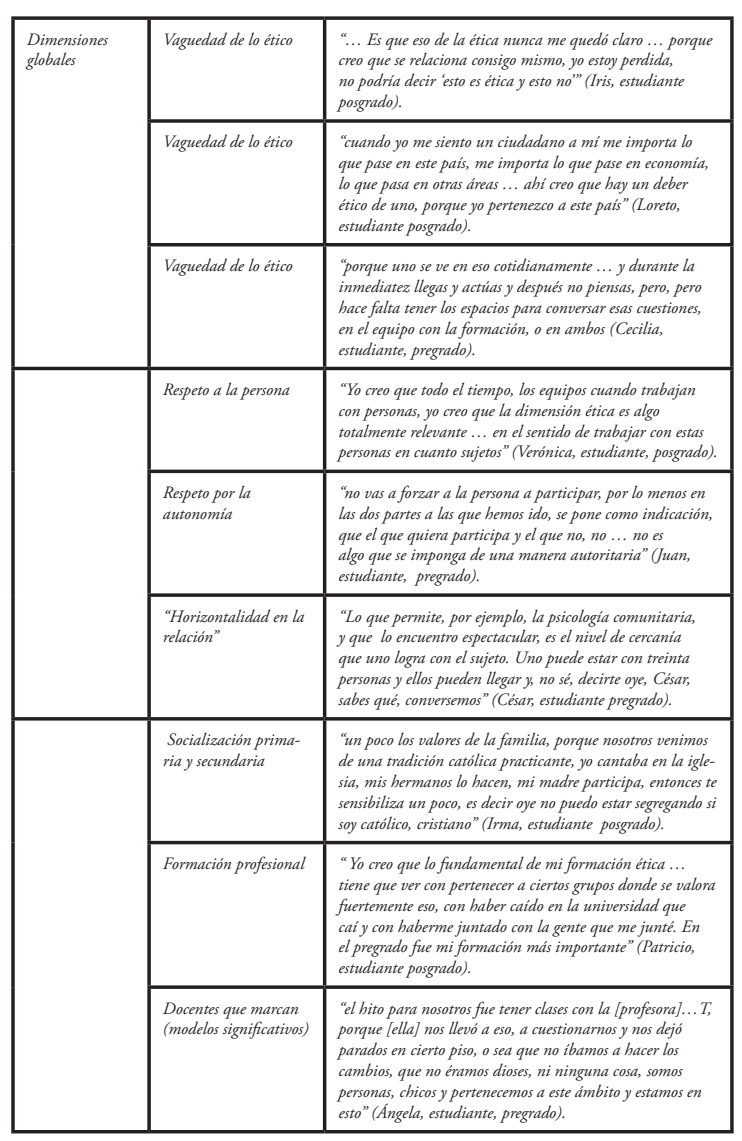

2. Tipos de situaciones éticas: aspectos del quehacer comunitario referidos como eventuales faltas éticas de las que se ha tenido conocimiento o conflictos enfrentados personalmente. Los clasificamos según la atribución que se hace a la causa u origen del problema. Encontramos, así, aquellos derivados del contexto macrosocial, otros situados entre el contexto y la institucionalidad, que atañen a las nociones difusas o problemáticas del quehacer comunitario. Tales "ambigüedades" evidencian situaciones de carácter ético que devienen de la institucionalidad o programas, del funcionamiento poco democrático, de intervenciones ineficientes o ineficaces y de sobreintervenciones. Los entrevistados describen problemas éticos derivadas del ejercicio profesional, como aspectos que interpelan sus competencias y el establecimiento de límites en la relación. En el caso de estudiantes, surgen problemas derivados de su práctica profesional. El siguiente cuadro contiene extractos de entrevistas y del panel Delphi que representan esta categoría.

\begin{tabular}{|c|c|c|}
\hline $\begin{array}{l}\text { Derivados } \\
\text { del contexto } \\
\text { macrosocial }\end{array}$ & \multicolumn{2}{|c|}{$\begin{array}{l}\text { "El cada vez más creciente individualismo y la desesperanza aprendida ante violaciones } \\
\text { a los derechos humanos. L vida en un sistema neoliberal que prioriza la viddeconómi- } \\
\text { ca o el interés en obtener dinero como un fin en si mismo y que también permite pagar } \\
\text { las infinitas deudas, lo cual se constituye en una barrera creciente para luchar por metas } \\
\text { comunes. Esto difculta la organización por temor a perder el trabajo, que es la fuente } \\
\text { que le permite pagar sus deudas" (Isabel, Panel Delphi). }\end{array}$} \\
\hline \multirow[t]{4}{*}{$\begin{array}{l}\text { Entre el } \\
\text { contexto y la } \\
\text { instituciona- } \\
\text { lidad }\end{array}$} & \multicolumn{2}{|c|}{ 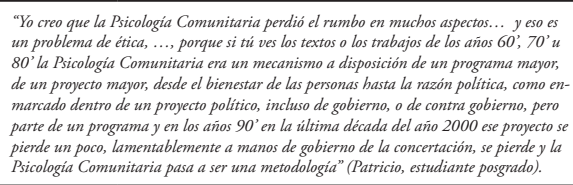 } \\
\hline & $\begin{array}{l}\text { Funciona- } \\
\text { miento poco } \\
\text { democrático }\end{array}$ & $\begin{array}{l}\text { "porque muchos problemas nacen desde las cabezas mayores hacia } \\
\text { abajo, es desde arriba hacia abajo y no desde abajo hacia arriba y } \\
\text { creo que ahi está el gran problema, de hecho se pierde mucho dinero } \\
\text { por lo mismo y no es porque ahi tengan malas intenciones o porque } \\
\text { hayan robos no, porque no se han preocupado de cosas tan básicas } \\
\text { como es ir donde la gente y tratar de ver las prioridades de ellos y no } \\
\text { las que yo pienso, porque yo estoy a cargo y yo soy el coordinador" } \\
\text { (César, estudiante, pregrado). }\end{array}$ \\
\hline & $\begin{array}{l}\text { Intervenciones } \\
\text { ineficientes } o \\
\text { ineficaces }\end{array}$ & $\begin{array}{l}\text { "Posee un carácter ético en cuanto tú les dices a las personas que } \\
\text { 'vamos a trabajar más sobre el proceso que deben tener como personas } \\
\text { para salir adelante o para desarrollar las capacidades que tienen', } \\
\text { porque eso era en lo que se enfocaba más el programa, y cuando, } \\
\text { posteriormente, no se trabajaba mucho con eso, sino que más } \\
\text { proyectos productivos y eso ya no importaba, ya no estabas haciendo } \\
\text { proceso de desarrollo, en eso entraba la contradicción" (Norma, } \\
\text { estudiante posgrado). }\end{array}$ \\
\hline & $\begin{array}{l}\text { Sobreinter- } \\
\text { vención }\end{array}$ & $\begin{array}{l}\text { "uno ve que hay gente que circula por los programas sociales y no } \\
\text { hay una cosa sucesiva, sino que hay familias que estan vinculadas } \\
\text { a tres intervenciones diferentes y no hay a veces coordinación de esos } \\
\text { equipos o no se les da sufciente tiempo o importancia y ... no puedes } \\
\text { osimplemente no te importa coordinar todas esas intervenciones" } \\
\text { (Verónica, estudiante posgrado). }\end{array}$ \\
\hline & Competencias & $\begin{array}{l}\text { "me parece importante la selección, de parte de las organizaciones } \\
\text { sociales, que cuando se hace selección, cuando contratas a un } \\
\text { profesional, ese profesional no tiene las competencias que se requieren; } \\
\text { porque a veces no se hace, porque sabes que si contratas al profesional } \\
\text { que realmente necesitas, con la formación que necesitas, tendrias que } \\
\text { pagarle más y las organizaciones justamente no hacen eso. Ahi hay } \\
\text { una responsabilidad, desde la formación académica, desde las organi- } \\
\text { zaciones sociales y desde el propio profesional, porque si te ofrecen un } \\
\text { trabajo al que tú no crees que das el ancho, tampoco estás obligado a } \\
\text { tomarlo" (Verónica, estudiante posgrado). }\end{array}$ \\
\hline & $\begin{array}{l}\text { Estableci- } \\
\text { miento de } \\
\text { limites en la } \\
\text { relación }\end{array}$ & $\begin{array}{l}\text { "éticamente eso de los limites es dificil ... manejarlos, porque no } \\
\text { sé, se supone que uno trabaja en la calle, en las casas incluso y acá, } \\
\text { igual se trata de enmarcar una estrategia diferente en el sentido del } \\
\text { lenguaje por ejemplo, los sobrenombres, los garabatos, el lenguaje que } \\
\text { ocupa uno, enmarcarlos pienso yo que es un poco dificil" (Carlos, } \\
\text { estudiante, pregrado). }\end{array}$ \\
\hline $\begin{array}{l}\text { Derivados de } \\
\text { la Práctica } \\
\text { Profesional de } \\
\text { estudiantes }\end{array}$ & \multicolumn{2}{|c|}{$\begin{array}{l}\text { "En los lugares de práctica uno se encuentra con que las necesidades son otras y no con las } \\
\text { que uno quiere llegar y decir, no, yo soy comunitario, trabajo con la gente, no allia. A mi } \\
\text { por lo menos me passo que tuve muchos problemas porque me imponian cosas que yo, a } \\
\text { mi juicio. éticamente no me involucraban" (César, sestudiante, pregrado). }\end{array}$} \\
\hline
\end{tabular}

3.- Formación ética en Psicología Comunitaria: refiere tanto a la forma como a los contenidos. Ninguna de las personas entrevistadas informó haber recibido formación específica en el tema; todas las referencias remiten a aprendizajes de as- 
pectos éticos generales, asociados a la psicología clínica. Observamos críticas a la formación recibida, desde las que se desprenden sugerencias, situadas fundamentalmente en el espacio académico y planteadas como metodologías: integración entre teoría y práctica; contenido clave: enfoque de derechos humanos, y una amplia gama de destrezas y/o actitudes a desarrollar en los estudiantes.

\begin{tabular}{|c|c|c|}
\hline $\begin{array}{l}\text { Formación re- } \\
\text { cibida (forma } \\
\text { y contenido) }\end{array}$ & \multicolumn{2}{|c|}{$\begin{array}{l}\text { "Recuerdo algunos cursos en que fue más tema, Metodologia de Intervención en Comu- } \\
\text { nidades, Evaluación o Metodologia Cualitativa, yo creo que ahí también vimos, quizás } \\
\text { porque estaban más vinculadas al tema práctico, o sea hacer una investigación cualitativa } \\
\text { de verdad, hacer algo más en terreno, y ahi esos profesores llevaban deliberadamente a esa } \\
\text { discusión ... Pero no podria decir que habia una falta de disposición, quizás cuando fue } \\
\text { necesario, cuando fue un tema directamente asociado al trabajo en terreno (Verónica, } \\
\text { estudiante de posgrado). }\end{array}$} \\
\hline $\begin{array}{l}\text { Críticas a la } \\
\text { formación } \\
\text { recibida }\end{array}$ & \multicolumn{2}{|c|}{$\begin{array}{l}\text { "De repente no hay tanto, asi como una pauta, o bien la universidad no le da énfasis } \\
\text { al tema ético, o será en general, porque igual hay tan poca cabida para la Psicologia } \\
\text { Comunitaria, yo supongo que hay conocimiento más en clinica que en comunitaria" } \\
\text { (Ana, estudiante de pregrado). }\end{array}$} \\
\hline & $\begin{array}{l}\text { Metodo- } \\
\text { lógica: } \\
\text { integración } \\
\text { entre teoría } \\
\text { praxis }\end{array}$ & $\begin{array}{l}\text { "Sobre ese trabajo práctico que es fundamental y central, tu puedes ir } \\
\text { girando el desarrollo conceptual en Psicologia Comunitaria para darle } \\
\text { orden y forma al trabajo práctico ..., en las primeras clases armas } \\
\text { el trabajo práctico, se arman los grupos, las semanas de terreno, una } \\
\text { supervisión constante y buena y como debe serlo y el trabajo conceptual } \\
\text { se arma en función de eso... porque la unica manera de darle contenido } \\
\text { ético es a través de mirarlo en la práctica, es poniéndolo sobre la base } \\
\text { de conflicto ético, no solo en la base de un texto" (Patricio, estudiante } \\
\text { de posgrado). }\end{array}$ \\
\hline & $\begin{array}{l}\text { Contenido } \\
\text { clave: } \\
\text { Derechos } \\
\text { Humanos }\end{array}$ & $\begin{array}{l}\text { "Aprender desde primer año la Declaración Universal de Derechos } \\
\text { Humanos,... Los Derechos Sexuales y Reproductivos, todo el tema de } \\
\text { los derechos de los inmigrantes, todas las declaraciones que hay, incluso } \\
\text { todo el marco teórico que hay de los derechos humanos, y también cómo } \\
\text { se incorpora eso en la práctica. Porque yo creo que igual vimos la ética, } \\
\text { pero sin un correlato con los derechos humanos" (Pamela, estudiante } \\
\text { de posgrado). }\end{array}$ \\
\hline & $\begin{array}{l}\text { Destrezas y/o } \\
\text { actitudes a } \\
\text { desarrollar } \\
\text { en los/as } \\
\text { estudiantes }\end{array}$ & 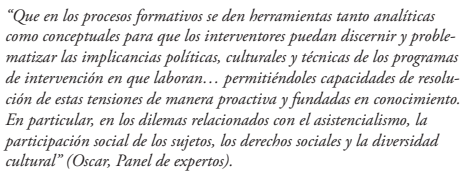 \\
\hline
\end{tabular}

4.- Deontología: refiere a las opiniones de nuestros participantes ante normativas explícitas respecto de lo correcto o incorrecto en el quehacer profesional, que evidencian una posición crítica ante la deontología, y minimiza y problematiza su atingencia al quehacer comunitario. Sin embargo, de la descripción de ciertos problemas se desprenden posibles lineamientos éticos relevantes de perfilar.

\begin{tabular}{|c|c|}
\hline $\begin{array}{l}\text { Posición ante la } \\
\text { deontologia }\end{array}$ & $\begin{array}{l}\text { "Es que no sé desde donde lo planteass, porque si es desde la academia, ... podrian } \\
\text { desarrollarse [normas], o no sé si las hay, podrian decir qué es ético hacer en una } \\
\text { comunidad, que es ético y qué no es ético en un trabajo comunitario, como para saber si } \\
\text { estás siendo ético o no; pero igual tiene que estar escrito o formulado en alguna parte... } \\
\text { porque me imagino que los médicos tienen cierta definiciones de lo que tienen que hacer" } \\
\text { (Iris, estudiante de posgrado. }\end{array}$ \\
\hline $\begin{array}{l}\text { Lineamientos } \\
\text { éticos para } \\
\text { la psicologia } \\
\text { comunitaria }\end{array}$ & $\begin{array}{l}\text { En la eventualidad de un código ético comunitario, cabria pensar con mayor } \\
\text { profundidad en los problemas propios de las intervenciones comunitarias, pienso que es } \\
\text { importante tener en cuenta que el psićlogo comunitario: } \\
\text { - no debe generar cambio en las comunidades sino solo propiciarlo, fomentar el desarrollo } \\
\text { desde las comunidades } \\
\text { - no debe atrincherarse bajo un bando de poder o un partido polititico en desmedro } \\
\text { de otro. } \\
\text { - si bien debe trabajar en pro de los más desvalidos y los que más necesitan, no por ello } \\
\text { debe dejar de lado a los lideres de la comunidad. } \\
\text { - no debe imponer criterios o actividades o procesos y ritmos de trabajo, solo debe } \\
\text { acompañar los procesos naturales de la comunidad, aunque piense que las decisiones de } \\
\text { la comunidad no son las más acertadas. } \\
\text { - debe asumir un rol de asesor y no de ejecutor ni de lider comunitario (Irma, } \\
\text { estudiante de posgrado. }\end{array}$ \\
\hline
\end{tabular}

A partir del análisis descriptivo, resumido previamente, y siguiendo la estrategia metodológica propuesta, elaboramos un análisis relacional, estableciendo vínculos entre categorías y subcategorías e identificando los elementos centrales que dan cuenta del fenómeno en estudio, plasmados en un modelo descriptivo-interpretativo que responde a los objetivos planteados: las formas en que perciben y se representan las dimensiones éticas nuestros informantes.

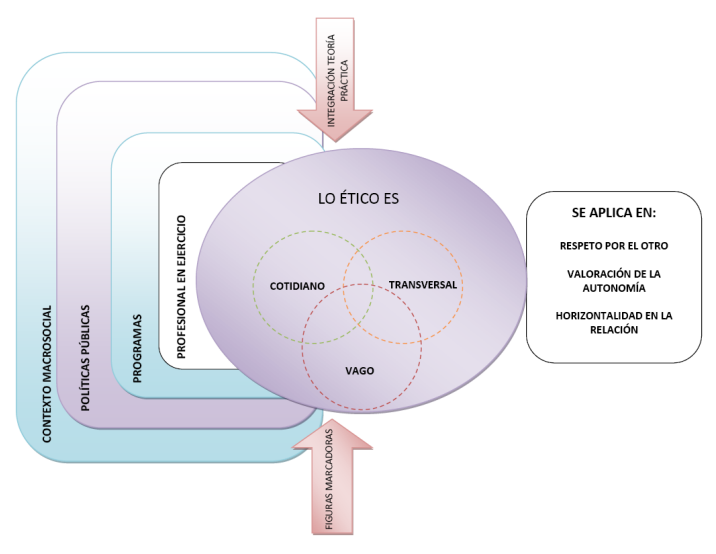

El diagrama grafica las coordenadas generales que retratan el contexto en que se juega la ética en psicología comunitaria en Chile hoy, organizada en niveles, desde lo macrosocial hasta lo individual: un sistema socioeconómico de libre mercado, con énfasis en el individualismo, más políticas públicas elaboradas sin participación de la comunidad y ejecutadas de "arriba hacia abajo", derivan en programas en que los psicólogos aparecen como técnicos, en un entorno laboral cada vez más precario e inespecífico.

Al centro del diagrama destaca una noción de lo ético como cotidiano y transversal, es decir, omnipresente, pero al mismo tiempo vago.

Respecto de la formación, se reconoce la importancia de figuras docentes marcadoras (flecha inferior), profesores que, por sus características personales y profesionales, influyen a los estudiantes en forma significativa, impregnándolos de responsabilidad por un ejercicio profesional ético. Asimismo, aparece la necesidad irrenunciable de integrar teoría y práctica en la formación (flecha superior), como un camino para facilitar el reco- 
nocimiento de las dimensiones éticas propias de la práctica. Esta concepción ética se aplica en el respeto por el otro y la valoración de la autonomía, y en una representación específica de la relación entre profesionales y usuarios, referida insistentemente como "horizontalidad en la relación" y definida en contraposición al encuadre clínico. i

\section{Discusión}

Estos resultados respecto de la noción de lo ético y los tipos de problemas éticos presentes en la práctica y la formación, nos obligan a cuestionar la influencia del contexto laboral y la calidad de la formación recibida por quienes se encuentran operando en psicología comunitaria. Del análisis relacional rescatamos la relevancia de tener conciencia de las limitaciones que impone un contexto que no reconoce ni valida una dimensión central de la psicología comunitaria, que es la participación de la comunidad en el diagnóstico de necesidades, diseño, implementación y evaluación de proyectos, por ejemplo, en salud mental comunitaria(5). Esta constituye una de las primeras implicancias éticas de nuestros hallazgos, tempranamente identificada como un costo de la institucionalización de la psicología comunitaria en el país(3) y que se manifiesta como un contrapunto al positivo incremento de plazas laborales para psicólogos en el ámbito público.

Una segunda implicancia ética se refiere al papel en que estos profesionales quedan subsumidos, en un aparataje público que determina desde la intencionalidad hasta la ejecución misma de los proyectos destinados a resolver las problemáticas de la comunidad, derivando en la transformación de la función profesional desde promotor del cambio social a operador de políticas y progra$\operatorname{mas}(5)$.

Por otra parte, se releva una concepción de lo ético como cotidiano y transversal, presente en la formación y en la práctica, y que da cuenta de una capacidad de identificar principios éticos universales en el quehacer profesional. No obstante, la coexistencia de una noción de lo ético como algo vago y difuso lleva a que esta conciencia no se cristalice ni en la identificación de temáticas específicas ni en la capacidad de discernir apropiadamente frente a situaciones concretas. Siguiendo los planteamientos de Rest y Narváez(26), no se dispondría de sensibilidad ética: la capacidad de darse cuenta e identificar situaciones de eventuales implicancias éticas. Lo concebimos, más bien, como una especie de "protosensibilidad", en que se intuye apenas la presencia de implicancias éticas, pero sin la habilidad de identificar cuál es la situación, en qué consiste y cómo enfrentarla.

Así, una tercera implicancia ética de estos resultados consiste en el develamiento de una situación de alto riesgo: estudiantes y profesionales, aunque conscientes de la relevancia de la ética en el quehacer profesional, carecen de las suficientes herramientas conceptuales, deontológicas y prácticas para abordar casos específicos. No obstante lo anterior, rescatamos la asunción de dos principios éticos universales - el respeto por el otro y la autonomía-, como un marco general para el quehacer profesional en psicología comunitaria que, de alguna manera, preserva el ethos fundador de esta disciplina.

Destaca la repetida alusión a lo que un entrevistado denomina "horizontalidad en la relación", y que pareciera consistir en una mayor cercanía y confianza entre profesionales y usuarios, que la propia del quehacer clínico. Este concepto de "horizontalidad" ha sido reportado previamente(27) por los propios usuarios de la práctica comunitaria, cuando valorizan especialmente la cercanía que perciben de los profesionales. No obstante, opinamos que esta verbalización refiere a una dificultad para diferenciar las características propias del encuadre clínico de las propias del encuadre comunitario. Si bien este último requiere un constante contacto y establecimiento de relaciones entre profesionales y usuarios, en distintos contextos temporales y geográficos, ello no implica la mal denominada "horizontalidad en la relación", ya que las diferencias de roles y estatus y poder asociados siguen vigentes. De este modo, encontramos que se diluye el significado y la forma en que se comprende lo que es ético o no, en este caso en la superposición de aspectos éticos - valoración del respeto por el otro y su autonomía- con aspectos técnicos del ejercicio profesional —especificidad del encuadre comunitario.

Respecto de la formación profesional, nuestros participantes confirman la importancia de la 
integración de teoría y práctica para lograr una adecuada identificación, comprensión y enfrentamiento de situaciones de implicancias éticas. Coincidimos con Arratia(12) al concebir el Aprendizaje en Servicio como instancia privilegiada para el logro de este objetivo. En concreto, postulamos como indispensable que la formación comunitaria comprenda trabajo en terreno, ya que la formación teórica en aula es insuficiente y no garantiza las condiciones necesarias para captar las implicancias éticas que devienen de las prácticas. Asimismo, es indispensable la reflexión sobre - y la decantación de- la experiencia. Solo a partir de este ejercicio sistemático será posible reconocer problemas éticos y formas de enfrentamiento propias del ámbito comunitario. Esta propuesta es concordante con la formación en ética profesional, concebida como un proceso de aculturación(8), yendo más allá de la transmisión de normativas específicas, y requiere, siguiendo a Rest(26), no sólo el desarrollo de la sensibilidad ética, sino de juicio ético, motivación ética y fuerza del yo. No basta la sensibilidad ética: es necesario poseer razonamiento ético para identificar una respuesta correcta, poseer la energía para hacer lo correcto y, más importante aún, la fuerza yoica necesaria para afrontar los costos de hacer lo correcto.

En una investigación previa(28) reportamos que los propios estudiantes proponen una formación ética que, además del conocimiento de la deontología específica, debe enfatizar el análisis y reflexión sobre casos concretos, así como también referir a situaciones de la propia vida académica.
Temas específicos refieren a quién es el cliente, cómo se resguarda la confidencialidad en el contexto comunitario y cómo se salvaguarda la relevancia de la participación de la comunidad cuando se trabaja en programas que vienen definidos desde las instancias centrales de poder.

Entre las fortalezas del estudio presentado destacamos el acceso a una diversidad de fuentes de información, asegurando rigor metodológico con la complementariedad de los datos y permitiendo acercarse al objeto desde distintas perspecti$\operatorname{vas}(29)$.

Como limitaciones señalamos el posible sesgo académico de nuestros participantes, expertos y estudiantes, y la escasa presencia de representantes de regiones del país, los que se reducen a tres expertos colaboradores en el panel Delphi.

Concluimos con la necesidad de futuras investigaciones, diversificando el perfil de informantes, incluyendo profesionales no académicos y que ejerzan fuera de la Región Metropolitana.

Es también indispensable incluir explícitamente las dimensiones éticas, teóricas y aplicadas, en la formación en psicología comunitaria. Pensamos que con ello sería posible avanzar en la operacionalización de principios, como respeto por el otro y autonomía, y en el decantamiento de orientaciones y guías para el ejercicio de la psicología comunitaria, demanda presente en la literatura y en la voz de nuestros participantes, y aún insatisfecha. 


\section{Referencias}

1. Asún D, Aceituno R, Alfaro J, Morales G, Krause M. La psicología comunitaria en Chile. Análisis de sus características y perspectivas. En Sánchez E, Wiesenfeld E. (eds.) Psicología Social Comunitaria, $1^{\text {a }}$ ed. Caracas: Tropykos; 1993: 151-188.

2. Alfaro J. Discusiones en psicología comunitaria, $1^{\text {a }}$ ed. Santiago de Chile: Universidad Diego Portales; 2000.

3. Krause M, Jaramillo A. Intervenciones Psicológico-comunitarias en Santiago de Chile, $1^{\text {a }}$ ed. Santiago de Chile: Pontificia Universidad Católica de Chile; 1998.

4. Krause M. Hacia una redefinición del concepto de comunidad. Cuatro ejes para un análisis crítico y una propuesta. Revista de Psicología de la Universidad de Chile 2001; X(2): 49-60.

5. Alfaro J. Políticas sociales como condición de posibilidad para el desarrollo de prácticas en psicología comunitaria. En Alfaro J, Berroeta H. (eds.) Trayectoria de la Psicología Comunitaria en Chile. Prácticas y Conceptos, $1^{\text {a }}$ ed. Valparaíso: Universidad de Valparaíso; 2007: 43-71.

6. Winkler MI, Pasmanik D, Alvear K, Reyes MI. Cuando el bienestar psicológico está en juego: La dimensión ética en la formación profesional de psicólogos y psicólogas en Chile. Revista Terapia Psicológica 2007; 25(1): 5-24.

7. Winkler MI. Cuestiones éticas en psicología comunitaria: dudas en la praxis. En: Alfaro J, Berroeta H. (eds.) Trayectoria de la Psicología Comunitaria en Chile. Prácticas y Conceptos, $1^{\mathrm{a}} \mathrm{ed}$. Valparaíso: Universidad de Valparaíso; 2007: 373-400.

8. Pasmanik D, Winkler MI. Buscando Orientaciones: Pautas para la Enseñanza de la Ética Profesional en Psicología en un Contexto con Impronta Postmoderna. Revista Psykhe 2009; 18(2): 37-49.

9. Diemer A, Frenzel I. Philosophie. Das Fisher Lexicon, Vol. 11. Frankfurt: Fischer Bücherei. 1960.

10. Orellana M. Pluralismo. Una ética del siglo XXI. $1^{\text {a }}$ ed. Santiago de Chile: Universidad de Santiago de Chile; 1994.

11. Cortina A. Ética Minima. Introducción a la fllosofía práctica. 13a ed. Madrid: Tecnos; 2008.

12. Arratia A. Ética, Solidaridad y "Aprendizaje Servicio" en la Educación Superior. Acta Bioethica 2008; 14(1).

13. Pope K. A Community Psychology of Ethics: Responding to "Responsible to Whom? Responsible for What"? American Journal of Community Psychology 1989; 17(3): 343-345.

14. Sánchez Vidal A. Ética de la intervención social, $1^{a}$ ed. Buenos Aires: Paidós; 1999.

15. Montero M. El paradigma de la psicología comunitaria y su fundamentación ética y relacional. En Montero M. Introducción a la psicología comunitaria, $1^{\text {a }}$ ed. Buenos Aires: Paidós; 2004: 41-53.

16. Montero M. Ética y política en Psicología. Las dimensiones no reconocidas. Athenea Digital 2001 abril: Disponible en: http://psicologiasocial.uab.es/athenea/index.php/atheneaDigital/article/ view/1/1

17. Montero M. Ethics and politics in psychology. Twilight dimensions. International Journal of Critical Psychology 2002; 1(6): 81-98.

18. Guba E, Lincoln Y. Competing Paradigms in Qualitative Research. En Denzin N, Lincoln Y. (eds.) Handbook of qualitative research. Thousand Oaks: Sage; 1994: 105-117.

19. Blanco A. La ética en la intervención social y comunitaria. Papeles del Psicólogo 1987 diciembre; 32. Disponible en http://www.cop.es/papeles/vernumero.asp?ID=343

20. Winkler MI. Nostalgia de un futuro: comunidad y ética. Ponencia presentada en el $3^{\text {er }}$ Encuentro de Psicología de Países Andinos: Integración Social, 8-10 diciembre. Escuela de Psicología, Universidad José Santos Ossa, Antofagasta, Chile, 2001.

21. González F. Epistemología y subjetividad. Revista Interamericana de Psicología 1998; 32(2): 139167.

22. Banyard V, Miller K. The powerful potencial of qualitative research for community psychology. American Journal of Community Psychology 1998; 26(4): 485-505.

23. Stein C, Mankowski E. Asking, witnessing, interpreting, knowing: conducting qualitative research in community psychology. American Journal of Community Psychology 2004; 33(1-2): 21. 
24. Astigarraga E. El método Delphi, 2004. Disponible en: http://www.codesyntax.com/prospectiva/ Metodo_delphi.pdf

25. Strauss A, Corbin J. Bases de la investigación cualitativa. Técnicas y procedimientos para desarrollar la teoría fundamentada. Bogotá: CONTUS Editorial, Universidad de Antioquia; 2002.

26. Rest J, Narvaez D. Moral development in the professions: psychology and applied ethics. Hillsdale, New Jersey: Lawrence Erlbaum Associates, Publishers; 1994.

27. Castilo J, Winkler MI. Praxis y Ética en Psicología Comunitaria: Representaciones Sociales de Usuarias y Usuarios de Programas Comunitarios en la Región Metropolitana. Revista Psyhke 2010; 19(1): 31-46.

28. Winkler MI, Pasmanik D, Alvear K. Informe Final Proyecto Fondecyt 1050009: La Ética en la formación y el ejercicio profesional de la Psicología en Chile: un diagnóstico multidimensional, 2008.

29. Cáceres M, García R. Fuentes de rigor en la investigación cualitativa. Universidad de Cienfuegos. Disponible en: http://www.bibliociencias.cu/gsdl/collect/revistas/index/assoc/HASH0197/ ef6fd6bc.dir/doc.pdf

Recibido: 10 de enero de 2011

Aceptado: 18 de abril de 2011 